\title{
Building a Sustainable Primary Care Workforce: Where Do We Go from Here?
}

\author{
Mark Linzer, MD, and Sara Poplau, BA
}

The article by Puffer et al in this month's JABFM confirms a high burnout rate (25\%) among family physicians renewing their credentials, with a higher rate among young and female doctors. Recent reports confirm high burnout rates among general internists. Thus, mechanisms to monitor and improve worklife in primary care are urgently needed. We describe the Mini $Z$ (for "zero burnout program") measure, designed for these purposes, and suggest interventions that might improve satisfaction and sustainability in primary care, including longer visits, clinician control of work schedules, scribe support for electronic medical record work, team-based care, and an explicit emphasis on work-home balance. (J Am Board Fam Med 2017;30:127-129.)

Those who practice primary care know, and the literature confirms, ${ }^{1}$ that we are simply working too hard. Burnout is prevalent, and it undermines morale, longevity, quality of care, and the career choices of medical students. ${ }^{2,3}$ The timely article by Puffer and colleagues ${ }^{4}$ in this issue of the $7 A B F M$ notes a somewhat lower rate of burnout than has been found in other studies. ${ }^{5}$ Yet their data indicate that $25 \%$ of family physicians renewing credentials report some level of burnout. Upwards of 22,000 family physicians may thus be facing depersonalization and exhaustion, with a consequent intent to leave their jobs or the field of medicine altogether. As a profession, and as a country, where do we go from here?

Before answering that question, several key features of the data from Puffer et $\mathrm{al}^{4}$ should be highlighted. First, why the lower (although still substantial) rate of burnout? The $100 \%$ response rate is remarkable, and suggests that those who did not

From the Office of Professional Worklife and Division of General Internal Medicine, Hennepin County Medical Center, Minneapolis MN.

Funding: none.

Conflict of interest: none declared.

Corresponding author: Mark Linzer, MD, Division of General Internal Medicine, Hennepin County Medical Center, Minneapolis, MN 55415 (E-mail: mark.linzer@hcmed.org).

See Related Article on Page 125. respond in previous surveys may have been less burned out. In addition, while the single-item burnout question from the Mini $\mathrm{Z}$ instrument (for "zero burnout program") correlates with the Maslach Burnout Inventory (MBI), prevalence of burnout obtained using this metric is often somewhat lower than studies using the full MBI. ${ }^{6}$

Second, why do younger physicians experience more burnout? This is often attributed to a "survivor cohort" of older physicians who have remained within the field while the burned out ones have left or chose to not renew their credentials. It is also possible that older physicians have determined over time how to be more resilient in the face of mounting work pressures. Work by Dyrbye et $\mathrm{al}^{7}$ confirms the higher burnout rate among younger and midcareer physicians. An important aspect of this result is that younger physicians, who are presumably more facile with electronic medical records (EMR) because of their computer skills, are not protected from burnout.

Third, why is there excess burnout among female physicians? The graph in the $\operatorname{article}^{4}$ shows a very high rate of burnout (close to $40 \%$ ) among young female physicians. In the late 1990s, we demonstrated excess burnout among female physicians, ${ }^{8}$ who experienced a faster pace of work, greater responsibilities at home, and a postulated "gendered expectation" by their many female patients for greater listening during office visits. The data shown by Puffer et al suggest that sex differ- 
ences in burnout may persist among certain subgroups (especially the young).

As we seek to address the crisis of high burnout rates among primary care providers, the Mini $Z$ may offer insights into interventions that can be expected to bring about change. Our team developed the Mini $Z$ as a brief (10-item) measure of stress, burnout, satisfaction, and their key remediable predictors, including teamwork, work control, work pace (chaos), time pressure, EMR work done at home, and lack of value alignment between clinicians and their leaders. The internal consistency is high, with a Cronbach $\alpha$ of $0.8,{ }^{6}$ whereas the single-item burnout measure correlates well with the emotional exhaustion component of the MBI. ${ }^{9}$ (Validation of the full Mini $\mathrm{Z}$ against the MBI is ongoing.) The tool was developed so that burnout could be measured in a clinic, institution, or discipline at baseline. Based on the item responses, targeted interventions could be instituted. Burnout and stress would then be remeasured in 6 to 12 months in a continuous quality improvement cycle, eventually driving burnout rates toward zero. Because the Mini $\mathrm{Z}$ is short, response rates tend to run high-from $47 \%{ }^{6}$ to well over $60 \%$ in other settings. ${ }^{10}$ The instrument is in the public domain and is available for use free of charge. In a recent study, we used the Mini $Z$ to assess burnout prevalence among a national sample of academic general internists. ${ }^{6}$ The burnout rate was $38 \%$, and the response to the other Mini $Z$ items generated a menu of opportunities for academic general internal medicine, including longer visits, control of schedule, emphasis on team-based care, and strategies to address EMR-related stress. We anticipate that the data from Puffer et al, ${ }^{4}$ using the other 9 Mini $\mathrm{Z}$ items, may generate a parallel set of recommendations for family medicine that can assist in national efforts to move the profession toward greater sustainability.

So where do we go from here to address a $25 \%$ rate of burnout among practicing family physicians and a greater than 1-in-3 rate among general internists? We propose focusing on the quadruple aim put forth by Bodenheimer and Sinsky, ${ }^{11}$ which includes using clinician wellness as a verifiable quality metric. To do this, practices and large health care systems will need to (1) allow clinicians to share control of schedules and workloads, (2) reduce stress brought on by the EMR by using scribes and EMR usability studies, and (3) promote team-based care. ${ }^{12,13}$ Acknowledging unique issues for younger women physicians in primary care will also be needed, ${ }^{8}$ adjusting for patient sex in compensation formulas and tracking their pace of work compared with male colleagues. Measuring workload and the ability to balance work-home responsibilities for both women and men physicians will allow a recalibration of clinicians' overall work efforts.

These suggestions are based on years of work and data by many investigators. ${ }^{2,7,8,10-13}$ Recent work by Shanafelt and Noseworthy ${ }^{14}$ elucidates the potential for leaders to embrace a wellness agenda and move their health systems toward a more balanced, engaged, and sustainable workforce. We applaud Puffer and his team for their new data. Let us put it to use promptly. The care of our patients, and the future of our profession, may depend on it.

To see this article online, please go to: http://jabfm.org/content/ 30/2/127.full.

\section{References}

1. Baron RJ. What's keeping us so busy in primary care? A snapshot from one practice. N Engl J Med 2010;362:1632-36.

2. Linzer M, Manwell LB, Williams ES, et al; MEMO (Minimizing Error, Maximizing Outcome) Investigators. Working conditions in primary care: physician reactions and care quality. Ann Intern Med 2009;151:28-36, W6-W9.

3. Hauer KE, Durning SJ, Kernan WN, et al. Factors associated with medical students' career choices regarding internal medicine. JAMA 2008;300: 1154-64.

4. Puffer JC, Knight HC, O’Neill TR, et al. Prevalence of burnout in board-certified family physicians. J Am Board Fam Med 2017;2:125-6.

5. Shanafelt TD, Mungo M, Schmitgen J, et al. Longitudinal study evaluating the association between physician burnout and changes in professional work effort. Mayo Clin Proc 2016;91: 422-31.

6. Linzer M, Poplau S, Babbott S, et al. Worklife and wellness in academic general internal medicine: results from a national survey. J Gen Intern Med 2016; 31:1004-10.

7. Dyrbye LN, Varkey P, Boone SL, Satele DV, Sloan JA, Shanafelt TD. Physician satisfaction and burnout at different career stages. Mayo Clin Proc 2013;88: $1358-67$.

8. McMurray JE, Linzer M, Konrad TR, Douglas J, Shugerman R, Nelson K. The work lives of 
women physicians: results from the Physician Work Life Study. The SGIM Career Satisfaction Study Group. J Gen Intern Med 2000;15: 372-80.

9. Rohland BM, Kruse GR, Rohrer JE. Validation of a single-item measure of burnout against the Maslach Burnout Inventory among physicians. Stress Health 2004;20:75-9.

10. Shimotsu S, Poplau S, Linzer M. Validation of a brief clinician survey to reduce clinician burnout. Abstracts from the 38th Annual Meeting of the Society of General Internal Medicine, Toronto, Canada: J Gen Intern Med 2015:30(2 Suppl): S79-80.
11. Bodenheimer T, Sinsky C. From triple to quadruple aim: care of the patient requires care of the provider. Ann Fam Med 2014;12:573-76.

12. Grumbach K, Bodenheimer T. Can health care teams improve primary care practice? JAMA 2004; 291:1246-51.

13. Bodenheimer T, Ghorob A, Willard-Grace R, Grumbach K. The 10 building blocks of high-performing primary care. Ann Fam Med 2014;12:166-71.

14. Shanafelt TD, Noseworthy JH. Executive leadership and physician well-being: nine organizational strategies to promote engagement and reduce burnout. Mayo Clin Proc 2017;92:129-46. 